\title{
Could coronavirus 2019-infected disease patients get cope with the treatment?: A qualitative study
}

\author{
Fery AM Mendrofa ${ }^{1}$, Umi Hani ${ }^{2}$, Yuni Nurhidayat ${ }^{3}$ \\ ${ }^{1,2}$ Department of Community Health Nursing, University of Karya Husada Semarang, Indonesia \\ ${ }^{3}$ Department of Medical-Surgical Nursing, Tugurejo Semarang Hospital, Indonesia
}

\begin{tabular}{l} 
Article Info \\
\hline Article history: \\
Received Feb 26, 2021 \\
Revised Aug 14, 2021 \\
Accepted Aug 25, 2021 \\
\hline
\end{tabular}

Keywords:

Coping

Coronavirus

Isolated patients

\begin{abstract}
A pandemic of a novel coronavirus-infected disease is currently ongoing in the world. Most patients have to be isolated due to the treatments. This study aimed to make sense of how patients with coronavirus-infected disease understand and experience infectious isolation. The research used a qualitative design with a phenomenological approach. Data collection was conducted with in-depth interviews of nine patients with coronavirus disease2019 (COVID-19) confirmed who had been in the isolation room. The analysis was conducted on interview transcripts by organizing keywords found into categories, sub-themes, and themes based on Colaizzi's approach. The results indicated that the participants experienced fright due to the isolation and attempted to integrate their isolation experiences. Isolation highlighted a sense of threat posed by cross-infection, a threat that participants experienced as originating from others and from themselves to others. Participants described feeling changes experienced after several days of treatment. Participants reported various symptoms of the disease and received careful care while in isolation. They still communicate with family. Isolated patients are able to deal with the treatment by improving their coping strategies. Participants reported the most support from their families, even from a distance. Future research could explore experiences of isolation from family and staff perspectives and identify the psychological aspect in caring for the COVID-19 patients.
\end{abstract}

This is an open access article under the CC BY-SA license.

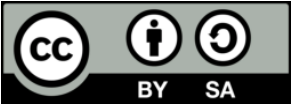

\section{Corresponding Author:}

Umi Hani

Department of Community Health Nursing

STIKes Karya Husada Semarang

Jl. R. Soekanto No.46, Sambiroto, Tembalang, Semarang City, Central Java, Indonesia

Email: umihani@stikesyahoedsmg.ac.id

\section{INTRODUCTION}

World Health Organization (WHO) declared Corona Virus Disease 2019 (COVID-19) as a public health emergency infectious disease that is a highly contagious viral pandemic affecting more than 12 million people in 216 countries around the world (as of July 14, 2020) on January 30, 2020. On March 11, 2020, WHO declared the COVID-19 as a pandemic [1]. Indonesia then declared COVID-19 as National Disaster on April 13, 2020. The Health Ministry of Indonesia announced that the total number of infections nationwide is 4,056,354 per August 27, 2021 [2]-[5].

Coronavirus disease, known as COVID-19, is a disease caused by a novel coronavirus (SARS_CoV2) that has recently emerged from China. Since the first case of COVID-19 in Wuhan, more than 200 countries have confirmed cases, and there have been 214,468,601 confirmed cases of COVID-19, including 4,470,969 deaths, reported to WHO by August 27, 2021 [6]. Indonesia is one of the countries where Covid- 
19 cases continue to increase. Data according to the Covid 19 Task Force, in March 2021, there were $1,368,069$ confirmed cases with 148,356 active cases $(10.8 \%$ of those confirmed), while $1,182,687$ cases recovered (86.4\% of confirmed cases), and 37,026 deaths (2.7\% of confirmed) [5], [7].

Person-to-person transmission has been described both in hospital and family settings [8], [9]. An infected patient could spread the virus through the respiratory droplets when coughing and sneezing. It is also transmitted from contact (shaking hands) with an infected person or a contaminated surface and transferring it to the mouth, nose, or eyes [10].

The mortality rate range is 0.8 to $4.3 \%$ based on the early data from different regions [11]. COVID19 is clinically reported with one or more mild symptoms of fever, malaise, cough, headache, body aches, dyspnea, and fatigue, with symptomatic recovery within a few weeks [3], [12], [13]. The vital signs were stable in most cases, while leucopenia and lymphopenia were common [13]. While severely affected patients show manifestations of progressive respiratory distress syndrome due to the lung substance damage and edematous changes caused by the virus, leading to shock and death in some cases [3]. A majority of middle to elderly patients with comorbidities including tumors, cirrhosis, hypertension, coronary heart disease, and diabetes are reported dead due to COVID-19 infections.

With disease progression, these clinical symptoms become severe and psychological problems in infected patients need to be targeted [14]. Studies have confirmed that the stress disorders experienced by individuals who have experienced public health emergencies should not be ignored even after the event is over, or they have been cured and discharged from the hospital. We should consider the disease course, severity of clinical symptoms, place of treatment (isolated at home, ordinary isolation ward, intensive care unit), and other factors to classify individuals who need psychological intervention and formulate specific measures to improve the interventions [15].

As a new disease, COVID-19 has various medical systems and cultures in different countries. It is essential to develop further research on the best practice in caring for isolated COVID-19 patients. Currently, published studies have highlighted the disease prevalence, clinical characteristics, diagnosis, and treatment [16]. Some reports have paid attention to the severity of psychological problems in patients and the urgency of providing psychological care in treatment. However, the data available regarding the psychological risks of COVID-19-infected patients and their coping strategies is still preliminary. In addition, the mental health needs of patients with confirmed COVID-19, patients with suspected infection, quarantined family members, and medical personnel have been poorly handled. The study aimed to understand patients' subjective experience in the isolation unit of COVID-19 through semi-structured interviews and to analyze the data using phenomenological methods, providing fundamental data for the coping process of patients.

\section{RESEARCH METHOD}

This study employed a qualitative design with a phenomenological approach. Data collection was carried out through in-depth interviews. The 9 COVID-19 patients in the isolation unit in Semarang, Central Java, Indonesia have indicated a willingness to participate in this study from May 2020 to June 2020. The data collection applied stringent health protocols. The researchers used personal protective equipment (PPE) includes gloves, PPE includes gloves, medical masks, Goggles, and a face shield, and gowns while interviewed the participants.

Data were gathered through in-depth interviews with nine patients using accidental sampling with inclusion criteria. The criteria were patients who were composmentis, able to communicate with nurses, and indicated a willingness to participate in this study. In-depth interviews were conducted in the isolation room in the COVID-19 unit of the hospital. The essential demographic information was collected using a demographic form. Informed consent was given to the participants to explain the ethical consideration in the study. Interviews were 30-45 minutes in length. All interviews were audiotaped and transcribed by a research team member, and some interview transcripts were returned to the participants for comment and correction. The analysis was conducted by thematic content analysis based on Colaizzi's approach. The keywords found in the interview transcripts organized into categories, sub-themes, and themes. The study was declared to have passed the ethical review by the Research Ethics Committee, University of Karya Husada Semarang No. 718/KH.KEPK/KT/III/2020. Written informed consent was obtained from all study participants.

\section{RESULTS AND DISCUSSION}

\subsection{Results}

\subsubsection{Characteristics of participants}

Participants are COVID19-infected patients cared for in the isolation unit of two hospitals in Semarang for 3-7 days. The characteristics of participants are shown in Table 1. All participants are residented in Semarang. 
Table 1. Socio-demographic characteristics of participants

\begin{tabular}{lc}
\hline Socio-demographic characteristics & Number (person) \\
\hline Gender & 5 \\
Man & 4 \\
Woman & \\
Age (years) & 4 \\
$21-30$ & 4 \\
$31-40$ & 1 \\
$41-50$ & \\
Marital status & 7 \\
Married & 2 \\
Single & \\
Length of hospitalization & 6 \\
< days & 3 \\
\hline 3 days & \\
\hline
\end{tabular}

\subsubsection{Interpretation of themes} treatment.

In the thematic analysis, five major themes emerged the adaptation process of all participants to

a) Psychological response to isolation treatment

All participant expressed their emotional process beyond their treatment in the isolation unit for COVID-19 patients. The patients feel fear, shock, and worry at the start of the treatment. The patient also rejects his condition and feels like going home.

“... I feel worried at first” (P1)

"I was sad ... I felt scared ... thoughts many things ..., and this room is so big for me alone..." (P1, P5)

"It felt surprised" (P3, P4, P5)

"I had argued" P5

"I feel, yeah ... worry" P5

"That time, I want to go home soon" (P4)

After several days of treatment, the patient feels lonely in the ward.

"I felt lonely" (P3)

"I was alone in this isolation room ...nobody else, no any friends" (P4, P2)

"I was wondering what will be treated for me in this isolation room" (P2)

"I feel lonely at night here" (P2)

"I have no friends here" (P2)

Patients could adapt to the treatment after one day through an adaptation process. In the process, patients were initiated by the shadow of the isolation space and fear of diseases emerging in the community. However, after undergoing treatment for one day, the situation in the isolation room was not as scary as they had previously imagined. Patients then pray and surrender to adhere the treatments that were planned for them.

"Feelings of fear like this are only one day. After passing one day here, it feels normal" (P1, P3)

"After a long time in this isolation room, being treated here, there is no problem" (P1, $\mathrm{P} 5, \mathrm{P} 9)$

"I think it's the terrible isolation room" (P1, P5, P7, P6)

"until I got it the blood went up" (P1, P3, P4, P7, P9)

"I just participated in the treatment, for the sake of healing and smoothness of both patients and nurses and doctors in this hospital" (P5)

"but what can I do" (P2) "my entertainment, only my cellphones."

"I just pray that what this doctor's diagnosis will soon disappear and disappear and my lung disease is also quickly finished... I continue to pray, sir, when I am in isolation... as best I can... pray five times a day ... and beg the creator, pray hopefully Get well soon" (P3, P5) 
"I'm grateful and always grateful, and thankful to all... doctors, employees and nurses who treat patients like me" (P5)

b) Perceived isolation treatment

As a newly emerged disease, the isolation treatment that the patient undergoes causes various subjective judgments to be felt by the patient. The services provided by nurses and other medical personnel are the basis for the patient's view of the isolation unit.

"The nurses are friendly. They give me some pieces of informatio clearly" (P1, P2, P5)

"The nurses care me very well. The care me appropriately" (P1, P2, P3, P5, P7, P9)

"The services are good enough here" (P5)

There were times when the nurse came late from the time, but the patient understood.

"Sometimes the nurse was a little delayed entering my room. But, it's gonna be oke. They are truly hero facing this kind of disease" (P5)

"They come to me as soon as possible when I need" (P1)

The care facilities were also influencing patients' perceptions of isolation treatments.

"It is a kind of comfort room, a bit windy, not too cold" (P1)

c) Signs of disease symptoms

It is well established that most patients with COVID-19 have respiratory signs and symptoms, such as cough, dyspnea, and other respiratory symptoms.

"I was coughing sir ... it felt itchy..." (P8)

"the coughing didn't stop ... so if the Javanese person coughed it cranky, and the mucus is hard to come out ... it takes a long time to come out" (P5)

"I feel short of breath. It feels short, and it hurts to the neck... it hurts as if you can't help it" (P3)

In particular, some observations with COVID-19 indicated that many patients present initially not necessarily with respiratory symptoms at first but with diarrhea, anorexia, and vomiting.

"My stomach is like being pulled ... it feels tight" (P5)

d) Patient's family response

Family support provides caregiving roles for the patients. The patient showed a psychological response in his family because he was COVID-19 confirmed.

"I was sad... My family were sad... I left behind... I should have joined Eid at home, but I should be here now..." (P2)

"My family felt surprised" (P5)

"How come COVID exposed me while I go nowhere. I never have any activities where and I just work in front of my computer" (P6)

Patients then tried to protect not only their selves but also their family.

"I warn my family to wear the mask. My family should be isolated, but sometimes they have to go out shopping" (P3)

e) Family support

Pressure from worrying about family reactions and needs could be one source of stress among COVID-19 infected patients. Nevertheless, patients experienced support from their family and colleagues, tried to take the disease as a live experience, and accepted the treatment in the isolation unit of a hospital to recover the disease. 
"My family gave me advice to be patient. Think of it as an experience in my life, then I must be optimistic for my healing" (P3)

"My family even encouraged me to be treated at the hospital... I hope the cough can be cured... I was infused here while If I was at home, I only took outpatient care and took medicine.... and I also often get hit by the night wind" (P4)

"Family support is getting bigger ... giving a motivation ... encouragement ... keep on going ... and sure that later I will be free from the virus .... even from friends, even to the headman myself, they told me ... and the message is just live the important thing to believe ... Yes... thank God there were many who gave me encouragement in the isolation" (P5)

The significant impact of family support in the recovery process makes the patients keep in contact with their families even if they could not meet one another. Therefore, the communication pattern of patients and their families were experienced by patients in increasing their motivation.

"I communicate freely with my family by my handphone" (P3)

"Smooth communication, with family, with friends, with everyone" (P4)

They used WhatsApp and video calls to communicate with their family.

"My family often contacted me" (P2)

"My brother... my elder brother kept in touch with me" (P6)

\subsection{Discussion}

The coronavirus disease 2019 (COVID-19) pandemic has spread globally over a swift period. Since the COVID-19 pandemic is very new, there is very little literature on the psychological impact of this pandemic. There are limited statistics about psychological health, mainly the prevalence of psychological problems among people during an epidemic outbreak. This study aimed to explore the experience of COVID19 confirmed patients and identify whether the patients found their coping strategies. In this case, coping strategies play a prominent role in maintaining mental health facing the disease. As COVID-19 is a new disease, it is still little known about the main coping strategies and potential, influential factors among patients with COVID-19 confirmed.

A sudden outbreak of a disease always poses a threat to the mental health of infected people and their close contacts. Confirmed patients, suspected patients, medical and related personnel, close contacts with patients may have a possibility of having a higher prevalence of these psychological problems regarding the high contagiousness and fatality [17], [18]. In addition, patients may fear death or spreading the virus to their family, friends, or close others [19].

Given the profoundly severe nature of the COVID-19 outbreak, it was not surprising that a significant proportion of patients studied experienced depression, anxiety [20]. The present study showed that confirmed COVID-19 patients experienced these feelings, particularly at the beginning of treatment in the isolation room. Patients were in loneliness and fear to face their death. As the other study, isolated and quarantined people experience stressful phenomena, such as losing face-to-face communication and other regular social intervention instigating from an epidemic outbreak [21]. In some previous epidemiological studies, depression, anxiety, negative psychological effect, panic attack, psychomotor excitement, psychotic symptoms, delirium, and even suicidal tendency have been found among the SARS epidemic survivors [22]. This psychological distress was a common symptom among isolated person. One study also showed that symptoms of depression were commonly reported among hospital quarantined COVID-19 patients, regardless of the severity of their illness [23].

The quarantined people feel boredom, loneliness, anger, depression, anxiety, denial, and may despair [17], [18], [20], [24]. Those who are quarantined, especially at the facilities outside their home, face an unprecedented situation of social isolation, social disconnectedness, loneliness, anxiety, depression, phobia, fear of getting the infection [25]. Anxiety, frustration, fear of causing infection, insomnia, and irritability are often the effects of isolation and quarantine. These short-term effects can even contribute to adjustment disorders and chronic post-traumatic stress syndrome. Substance use tends to be increased. Ensuring patients in isolation have adequate dignity and supplies are vital. Early supportive interventions and facilitating social connections for them help reducing loneliness. Their families need to be kept wellinformed with comprehensive, updated yet relevant facts to reduce their fear of uncertainty [26]. Another study on COVID-19-infected individuals who were obligatorily quarantined at King Abdullah University Hospital, Irbid, Jordan demonstrated that watching or reading news about COVID-19 during quarantine was associated with higher levels of depression [23]. 
Patients felt the denial due to the stress, mental agony, and internalized stigma. Patients also have feelings of guilt and worry of infecting near and dear ones, the shame of infecting others, anger directed towards self, cursing one's fate, thinking "why God has punished me and my family" adds on to the pain of remaining socially isolated from the family in a 'locked up' state is highly distressing [27]. Moreover, physical symptoms of COVID-19 such as fever, hypoxia, and cough, and adverse effects of prescribed medications (corticosteroids) may cause more anxiety and mental distress [17].

Patients showed positive coping in dealing with COVID-19. They were infected by surrendering to God. As stated by other studies, a relationship with God helped patients provide support and strength to deal with the consequences of a stigmatized and fatal disease, such as COVID-19. A positive and significant correlation between depression and avoidant coping in a study reflected that the higher the level of depression, the greater the degree of engagement in avoidant coping and vice versa. Due to limited resources and poor health-seeking behavior (limited understanding of the nature of disease), the subjects had little scope for active coping, so they preferred avoidant coping [28]. In addition, patients need to be exposed to information sources to increase their behavior related to their disease.

To avoid a distressing situation, individuals should not get overexposed to media coverage, maintain a healthy relationship, get in touch with friends and family members regularly using social media, and start thinking positively. In addition, if coronavirus anxiety shows up, try to share the fear with others, which will calm the fear, and try to increase self-awareness by getting adequate sleep, exercising regularly, and employing different relaxation techniques [29].

The feeling of anger was not reported, which might be related to mild symptoms experienced by the patients. Fright of the consequences of infection and the uncertainty about the infection treatment are the two leading causes of the negative feelings and thoughts among COVID-19 patients [19], [30]. On the other hand, post-traumatic stress symptoms differed more significantly across outbreaks. Studies exploring the impact of the Ebola epidemic, in particular, often featured post-traumatic stress symptoms as a main theme. As COVID-19 is a new disease, the present study may underlie possible post-traumatic stress symptoms for isolated COVID-19 patients.

A study provides an insight into the negative psychological effects and associated problems of COVID-19. The study showed that the corona infection experienced by patients is not always the initial cause of the emergence of psychological problems such as anxiety, depression, and alcohol use disorders. Indeed, we need to consider the indirect effects such as being isolated from family and friends and death that affect overall mental health well-being [22].

Individuals who have experienced public health emergencies still have varying degrees of stress disorders, even after the event. Although they have recovered and been discharged from the hospital, indicating these individuals should not be ignored [14]. Finally, psychological intervention is needed to prevent psychological problems among isolated patients with COVID-19. COVID-19 patients found reasons to distract themselves from the emerging situation by performing external actions and resorted to mental avoidance. Patients keep the contact with their family as their support to survive against the disease [23]. They tend to reject their confirmed disease at first, but they accepted their condition later and tried to survive the disease. Support from the patients' family is an essential aspect of recovery, and the family also has specific needs to be considered - psychological, physical, emotional, social, and financial [23].

Some patients sought professional assistance to address their questions or identify coping strategies before becoming overwhelmed by the experience. Others stated they found inner strength that they had not known they possessed. Still, others could not identify strategies they had used until several weeks after treatment was finished. Regardless of when the patients identified their strategies, there were five common coping strategies: seeking information, discovering inner strength, relying on a support network, establishing a sense of normalcy, and finding meaning within the experience. Previous studies have emphasized the significant association between confidence and gathering information as part of active coping with COVID19 [31]. However, another study stated that confidence failed to significantly mediate the association between perceived social support and active coping with COVID-19. Thus, it is necessary to enhance perceived social support and specific resources to facilitate social interaction under adequate infection control. Regarding the negative impact of internet use, it is still necessary to promote telecommunication, online gathering, or social interaction programs at the difficult time of social distancing to enhance the perceived social support [29], [32].

Mental health professionals need to recognize that besides anxiety, depression, insomnia, guilt, anger, frustration, and internalized stigma are also going to be the major issues of these patients and need to address the same [27]. The present study suggests that apart from the psychological issues of the health care workers, there is an urgent need to handle and understand the mental health issues of the patients suffering from COVID-19 during admission/ward stay and during quarantine [26]. The uncertainty of having a dreadful illness, limited family support, fear of death, and near ones imposes a severe stressful mental state. Therefore, mental health evaluation and mental health support for the patients need to be routinely done.

Could coronavirus 2019-infected disease patients get cope with the treatment?: A ... (Fery AM Mendrofa) 
Based on our experience, we suggest that all the COVID-19 wards and services should plan to keep the people's mental health at large. All COVID-19 wards and other services should have mental health professionals, who should be involved right from screening the persons for COVID-19. It is important to understand that the impact of the COVID-19 pandemic extends beyond that of physical illness. We would say that it has mental health impact on more people than those experiencing the physical health impact [33].

\section{CONCLUSION}

This study described the experiences of isolated COVID-19 patients, highlighting the coping process that the patients experience during their treatment in the isolation unit. These include physical and psychological feelings. The coping strategies in facing the COVID-19 treatments involved seeking information from multiple sources such as health care providers or the internet, discovering inner strengths to survive, relying on a support network of family and friends, and finding deeper meaning in the experience of giving back. Nurses should provide personal and interpersonal support as patients experience the consequences of the disease and its treatment. Nurses can encourage patients to identify and employ effective coping strategies. Nurses can also help patients find ways to advocate at the social system level, reducing the actual or perceived social stigma for the patients.

Limitations in this study include the subjectivity of the researcher. This research is very dependent on the researcher's interpretation of the meaning implied in the interview so that the tendency for bias still exists. A triangulation process was carried out through source and method triangulation. First, the data was cross-checked with facts from different informants and other research results as a triangulation of sources. Then, the researchers used in-depth interview and observation methods as the triangulation of methods. In addition, the situation where the interview was in the isolation room, and researchers who had to use a complete PPE are also limitations that affect the depth of the interview results. For further research, it is necessary to consider other locations that have unique characteristics or cultural backgrounds so that it is possible to obtain variations of research data. In addition, it is necessary to develop research with experiments that can assess the effectiveness of interventions or programs for isolated patients to pass the isolation period adaptively.

\section{REFERENCES}

[1] D. Cucinotta and M. Vanelli, "WHO Declares COVID-19 a Pandemic," Acta Biomed., vol. 91, no. 1, pp. 157-160, Mar. 2020, doi: 10.23750/abm.v91i1.9397.

[2] I. Abdullah, "COVID-19: Threat and Fear in Indonesia," Psychol. Trauma Theory, Res. Pract. Policy, vol. 12, no. 5, pp. 488-490, 2020, doi: 10.1037/tra0000878.

[3] A. Naseer, M. Shakoor, F. Vohra, T. Abduljabbar, Q. Mariam, and M. A. Rehman, "Knowledge, Awareness and Practice of Health care Professionals amid SARS-CoV-2, Corona Virus Disease Outbreak," Pak. J. Med. Sci. Q., vol. 36, no. S4, May 2020.

[4] Ministry of Health RI, "Situasi Virus Covid-19 di Indonesia," 2021, [Online]. Available: https://covid19.go.id/. (Accessed: 28-Aug-2021).

[5] Y. Bachri and A. S. Utami, "The Effect of Whatsapp-Based Education on Adolescent Self Awareness for the Implementation of the Prevention of Covid-19 Transmission (In Indonesia: Pengaruh Edukasi Berbasis Whatsapp terhadap Self Awareness Remaja untuk Penerapan Pencegahan Penularan COVID-19)," J. Ilmu Keperawatan Jiwa, vol. 4, no. 3 SE-Articles, pp. 537-544, Aug. 2021.

[6] World Health Organisation, "RCCE Action Plan Guidance Covid-19 preparedness \& response," p. 26, 2020, [Online]. Available: https://www.who.int/publications-detail-redirect/risk-communication-and-communityengagement-(rcce)-action-plan-guidance.

[7] Ministry of Health RI, "Decree of the Minister of Health of the Republic of Indonesia number hk.01.07/menkes/328/2020 regarding guidelines for preventing and controlling COVID-19 (In Indonesia: Keputusan menteri kesehatan republik indonesia nomor hk.01.07/menkes/328/2020 tentang panduan pencegahan dan pengendalian COVID-19)," [Online]. 2020, Available: http://hukor.kemkes.go.id/uploads/produk_hukum/KMK_No_HK_01_07-MENKES-3282020_ttg_Panduan_Pencegahan_Pengendalian_COVID-19_di_Perkantoran_dan_Industri.pdf

[8] G. Kampf, D. Todt, S. Pfaender, and E. Steinmann, "Persistence of coronaviruses on inanimate surfaces and their inactivation with biocidal agents," J. Hosp. Infect., vol. 104, no. 3, pp. 246-251, 2020, doi: 10.1016/j.jhin.2020.01.022.

[9] K. Wang, W. Zhao, J. Li, W. Shu, and J. Duan, "The experience of high-flow nasal cannula in hospitalized patients with 2019 novel coronavirus-infected pneumonia in two hospitals of Chongqing, China," Ann. Intensive Care, vol. 10, no. 1, 2020, doi: 10.1186/s13613-020-00653-z.

[10] X. Tang et al., "On the origin and continuing evolution of SARS-CoV-2," Natl. Sci. Rev., vol. 7, no. 6, pp. 10121023, 2020, doi: 10.1093/nsr/nwaa036.

[11] C. Calisher et al., "Correspondence Statement in support of the scientists , public and medical professionals of 
China," Lancet, vol. 6736, no. 20, pp. 9-10, 2020, doi: 10.1016/S0140-6736(20)30418-9.

[12] S. P. Adhikari et al., "A scoping review of 2019 Novel Coronavirus during the early outbreak period: Epidemiology, causes, clinical manifestation and diagnosis, prevention and control," Research Square, pp. 1-12, 2020, doi: 10.21203/rs.2.24474/v1.

[13] D. S. Hui et al., "The continuing 2019-nCoV epidemic threat of novel coronaviruses to global health — The latest 2019 novel coronavirus outbreak in Wuhan, China," Int. J. Infect. Dis., vol. 91, pp. 264-266, 2020, doi: 10.1016/j.ijid.2020.01.009.

[14] L. Duan and G. Zhu, "Psychological interventions for people affected by the COVID-19 epidemic," The Lancet Psychiatry, vol. 7, no. 4, pp. 300-302, Apr. 2020, doi: 10.1016/S2215-0366(20)30073-0.

[15] N. Easom et al., "Sixty-eight consecutive patients assessed for COVID-19 infection: Experience from a UK Regional infectious diseases Unit," Influenza Other Respi. Viruses, vol. 14, no. 4, pp. 374-379, 2020, doi: 10.1111/irv.12739.

[16] N. Sun et al., "A qualitative study on the psychological experience of caregivers of COVID-19 patients," Am. J. Infect. Control, vol. 48, no. 6, pp. 592-598, 2020, doi: 10.1016/j.ajic.2020.03.018.

[17] C. Wang et al., "Immediate Psychological Responses and Associated Factors during the Initial Stage of the 2019 Coronavirus Disease (COVID-19) Epidemic among the General Population in China," International Journal of Environmental Research and Public Health, vol. 17, no. 5. 2020, doi: 10.3390/ijerph17051729.

[18] W. Li et al., "Progression of mental health services during the COVID-19 outbreak in China," Int. J. Biol. Sci., vol. 16, no. 10, pp. 1732-1738, 2020, doi: 10.7150/ijbs.45120.

[19] Y. T. Xiang et al., "Timely mental health care for the 2019 novel coronavirus outbreak is urgently needed," The Lancet Psychiatry, vol. 7, no. 3, pp. 228-229, 2020, doi: 10.1016/S2215-0366(20)30046-8.

[20] Q. Guo et al., "Immediate psychological distress in quarantined patients with COVID-19 and its association with peripheral inflammation: A mixed-method study," Brain. Behav. Immun., vol. 88, pp. 17-27, 2020, doi: 10.1016/j.bbi.2020.05.038.

[21] J. Zhang, W. Wu, X. Zhao, and W. Zhang, "Recommended psychological crisis intervention response to the 2019 novel coronavirus pneumonia outbreak in China: a model of West China Hospital," Precis. Clin. Med., vol. 3, no. 1, pp. 3-8, 2020, doi: 10.1093/pcmedi/pbaa006.

[22] M. Z. Ahmed, O. Ahmed, Z. Aibao, S. Hanbin, L. Siyu, and A. Ahmad, "Epidemic of COVID-19 in China and associated Psychological Problems," Asian J. Psychiatr., vol. 51, p. 102092, 2020, doi: https://doi.org/10.1016/j.ajp.2020.102092.

[23] S. M. Samrah et al., "Depression and Coping Among COVID-19-Infected Individuals After 10 Days of Mandatory in-Hospital Quarantine, Irbid, Jordan," Psychol. Res. Behav. Manag., vol. 13, pp. 823-830, 2020, doi: 10.2147/PRBM.S267459.

[24] L. Dong, J. Bouey, and J. Bouey, "Public Mental Health Crisis during COVID-19 Pandemic, China," Emerg. Infect. Dis., vol. 26, no. 7, pp. 1616-1618, 2020, doi: 10.3201/eid2607.200407.

[25] S. K. Brooks et al., "The psychological impact of quarantine and how to reduce it: rapid review of the evidence," Lancet, vol. 395, no. 10227, pp. 912-920, 2020, doi: 10.1016/S0140-6736(20)30460-8.

[26] D. Banerjee, "The COVID-19 outbreak: Crucial role the psychiatrists can play," Asian J. Psychiatr., vol. 50, p. 102014, 2020, doi: 10.1016/j.ajp.2020.102014.

[27] S. Sahoo et al., "Lived experiences of the corona survivors (patients admitted in COVID wards): A narrative reallife documented summaries of internalized guilt, shame, stigma, anger," Asian J. Psychiatr., vol. 53, p. 102187, May 2020, doi: 10.1016/j.ajp.2020.102187.

[28] S. Kaneez, "Depression and coping mechanism among HIV/AIDS patients under anti-retroviral therapy," Indian J. Soc. Psychiatry, vol. 32, no. 2, pp. 149-153, Apr. 2016, doi: 10.4103/0971-9962.181098.

[29] S. K. Kar, S. M. Y. Arafat, R. Kabir, P. Sharma, and S. K. Saxena, Coping with Mental Health Challenges During COVID-19. In: Saxena S. (eds) Coronavirus Disease 2019 (COVID-19). Medical Virology: From Pathogenesis to Disease Control. Singapore: Springer, 2020.

[30] S.-W. Kim and K.-P. Su, "Using psychoneuroimmunity against COVID-19," Brain. Behav. Immun., vol. 87, pp. 45, 2020, doi: 10.1016/j.bbi.2020.03.025.

[31] P.-W. Wang et al., "COVID-19-Related Information Sources and the Relationship With Confidence in People Coping with COVID-19: Facebook Survey Study in Taiwan," J. Med. Internet Res., vol. 22, no. 6, p. e20021, Jun. 2020, doi: 10.2196/20021.

[32] D.-J. Li, Nai-Ying Ko, Yu-Ping Chang, Cheng-Fang Yen, and Yi-Lung Chen, "Mediating Effects of Risk Perception on Association between Social Support and Coping with COVID-19: An Online Survey," Int. J. Environ. Res. Public Health, vol. 18, no. 4, p. 1550, 2021, doi: 10.3390/ijerph18041550.

[33] S. Grover, D. Dua, S. Sahoo, A. Mehra, R. Nehra, and S. Chakrabarti, "Why all COVID-19 hospitals should have mental health professionals: The importance of mental health in a worldwide crisis!," Asian J. Psychiatr., vol. 51, p. 102147, 2020, doi: 10.1016/j.ajp.2020.102147. 